\title{
Relaciones México-Japón
}

Melba Falck Reyes

Héctor Palacios

\section{El japonés que conquistó Guadalajara}

La historia de Juan de Páez en la Guadalajara del siglo xVII

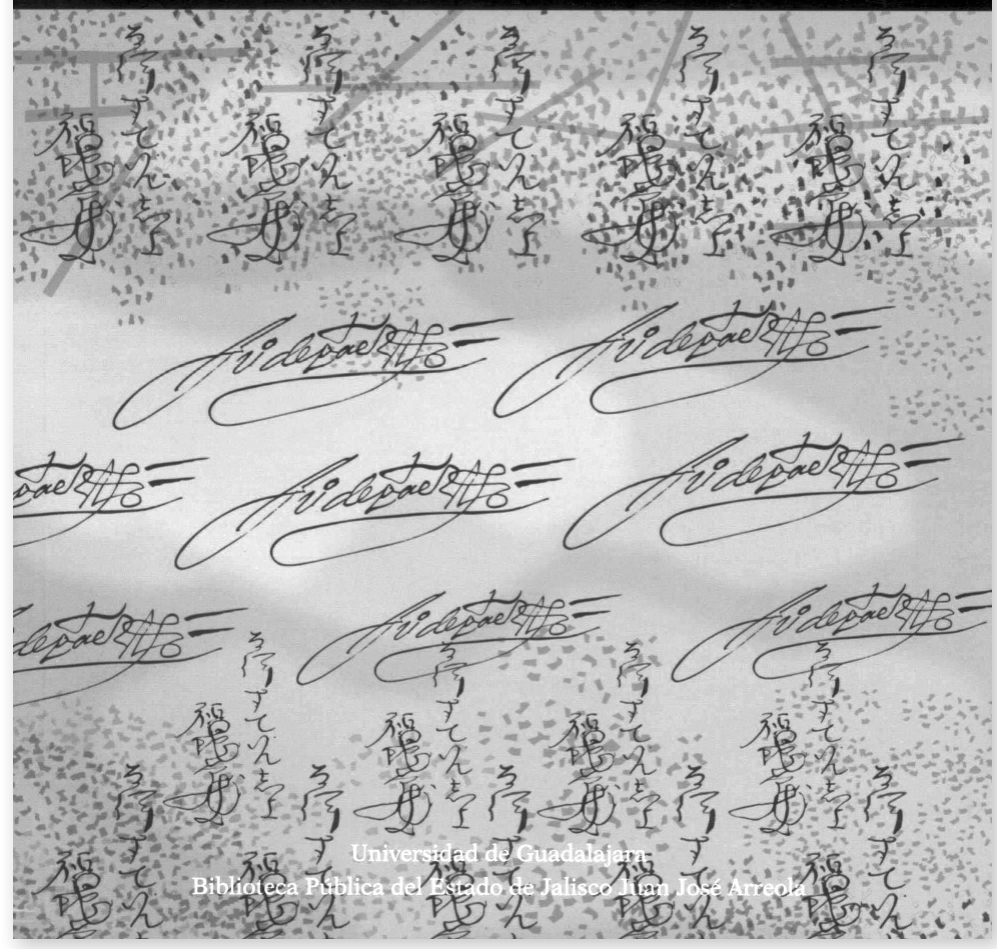




\section{RESEÑA}

\section{El japonés que conquistó \\ Guadalajara: La historia de Juan de Páez en la Guadalajara del siglo XVII}

DOI: $10.32870 /$ mycp.v14i40.363

Guillermo Ruiz-Stovel ${ }^{1}$

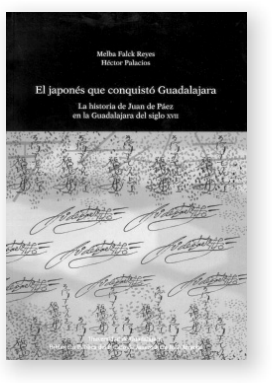

El japonés que conquistó Guadalajara: La historia de Juan de Páez en la Guadalajara del siglo XVII Melba Falck y Héctor Palacios Universidad de Guadalajara, 178 páginas, 2010

$\mathrm{E}$ n 1601, aproximadamente una década antes de la llegada de Juan de Páez a tierras novohispanas, el jesuita italiano Matteo Ricci se convirtió en el primer europeo en poner pie en la "ciudad prohibida", un raro honor sujeto por expresa invitación del emperador, quien se encontraba particularmente interesado en la erudición matemática del misionero. Para entonces Ricci había residido 20 de sus 49 años en el sur de China, abocado al estudio del chino antiguo y de los clásicos confucianos, incluso adoptando el nombre chino Li Madou y la vestimenta de los mandarines.

Ante estas circunstancias, puede que la "conquista" de la Guadalajara fundacional por parte de un inmigrante japonés parezca una empresa más

1. Estudiante del Doctorado en Historia en la Univesidad de California en Los Ángeles (UCLA). ORCID http:// orcid.org/0000-0001-6873-8704 
bien modesta. Sin embargo, la vida que rescatan Melba Falck y Héctor Palacios con este trabajo no resulta nada menos que extraordinaria. Páez no penetraría al interior de la corte manchú, pero sí lograría catapultarse hasta los más altos estratos sociales de la Guadalajara colonial, donde las divisiones no eran sólo económicas sino también producto de un complejo sistema de clasificación racial. Su mera existencia parece poner de cabeza la concepción generalizada del México colonial como un universo regido por el hermetismo y la intolerancia.

El hombre que conocemos como Juan de Páez se trasladó de su natal Osaka a la Nueva España siendo todavía un niño, al parecer en la orfandad y bajo el cobijo de la Iglesia. Impulsado por el inusual éxito comercial de su suegro, el también japonés Luis de Encío (de especulado origen samurai), y muy probablemente contando con una privilegiada educación jesuita, Páez se perfilaría como un "blanco honorario", convirtiéndose en el albacea predilecto de la élite tapatía. Además fungiría como mayordomo de la Catedral de Guadalajara por poco más de dos décadas, desde 1654 hasta su muerte en 1675. En términos más contemporáneos, Páez hacía de asesor patrimonial y a la vez de administrador local para la transnacional más grande e influyente de la época. Consta en los archivos que Páez además llegó a ser temporalmente corregidor de Zapopan y que realizó una fuerte inversión en la compra de esclavos a lo largo de su vida, habiendo registro de casi una treintena de negros y mulatos que llegaron a ser parte del patrimonio de la familia Páez-Encío.

El japonés que conquistó Guadalajara versa no sólo sobre el Juan de Páez histórico, sino también del Juan de Páez historiográfico, cuyo esbozo misterioso llevaría a la creación de este libro. La interesante genealogía de este segundo Páez se remonta a poco más de medio siglo, empezando con el historiador tapatío Juan Palomino y Cañedo, quien con una breve mención inspiraría al historiador francés Thomas Calvo a escribir un artículo sobre los japoneses en la Guadalajara del siglo XVII, publicado en 1983. Eikichi Hayashida, entonces embajador japonés en España, leería con fascinación el relato de Calvo, y tras una visita a Guadalajara en 2002, "encomendaría" a Falck la tarea de efectuar las indagaciones pertinentes. Convertida posteriormente en una confesa apasionada por el enigma de Páez, Falck incorporaría a Palacios, un joven historiador, para colaborar en la pesquisa, completando así lo que Calvo ha llamado el "cuarto eslabón" detrás de esta historia.

Al igual que el citado Ricci, el Juan de Páez histórico es representativo de una era de transformaciones y nuevas dinámicas intercontinentales. Sin 
embargo, a diferencia de Ricci, la vida de Páez transcurre enteramente en la periferia de la historia eurocéntrica. Pero si consideramos, tal y como propone la "nueva historia mundial", que Asia era el verdadero centro y motor de una economía incipientemente global, la historia de Páez no sólo salta de los márgenes sino que se entreteje con uno de los principales hilos conductores de esta nueva narrativa histórica. El corredor transpacífico que unió al México colonial con el Este asiático, con sus casi 250 años de actividad, continúa siendo hoy fuente de grandes incógnitas: son pocas las biografías de los "pasajeros" que conocemos en detalle, y la abrumadora mayoría ha sido condenada al anonimato. Con los hallazgos de Falck y Palacios, Juan de Páez se convierte en la más reciente añadidura a esta breve lista de pasajeros célebres, entre ellos Felipe de las Casas (1572-1597), primer santo mexicano, y Mirra Catarina de San Juan (1606-1688), ascética esclava originaria de la India e inspiración tras la "china poblana".

Sobra decir que esta obra, producto de siete años de trabajo, representa una importante contribución al estudio de la historia regional y de las relaciones México-Japón. Su publicación coincide incidentalmente con el 400 aniversario de la relación bilateral, en una edición conmemorativa con 19 láminas a color, en su mayoría fotografías de objetos históricos de colecciones locales. Éste es además un trabajo que nos habla de un importante periodo en la historia global y cuyo interés trasciende más allá de la historiografía convencional. Además de los pendientes por esclarecer enumerados por los autores en el último capítulo, yo señalaría el reto de difundir estos hallazgos más allá de la comunidad intelectual hispanoparlante, estableciendo vínculos con estudiosos de la historia transpacífica en Europa, Asia y América que permitan descubrir nuevas piezas del rompecabezas. Porque aunque el Juan de Páez histórico tenga más de 300 años sepultado en la Catedral de Guadalajara, al segundo Juan de Páez le queda una larga vida por delante. 


\section{Relaciones Internacionales:}

teoría y práctica

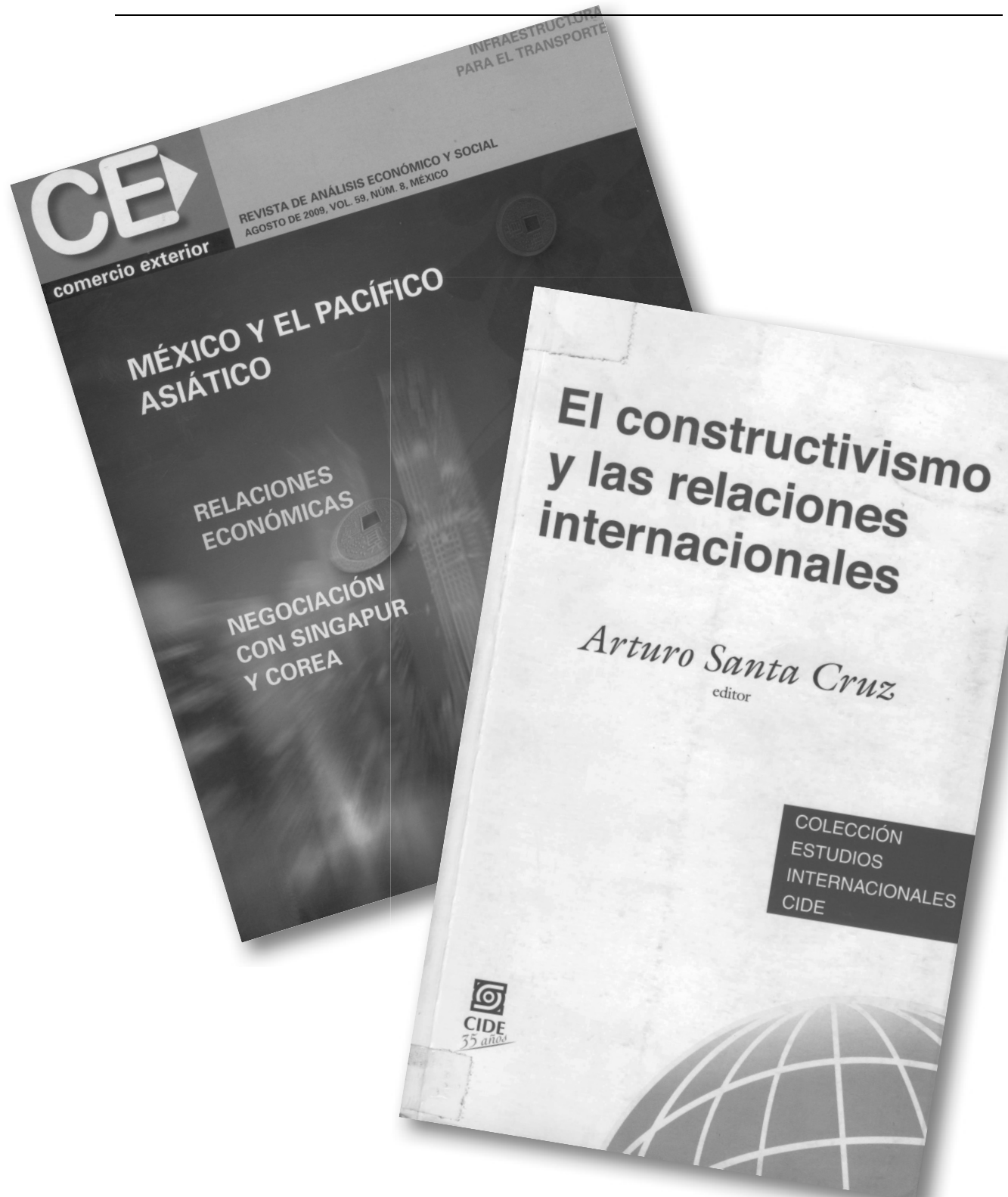

